\title{
Construction and Practice of Course System Millitary and Political Quality Based on "Orientation Training Sergeant"---Taking Binzhou Polytechnic Ocean Department as an Example
}

\author{
Yonggang Zong ${ }^{\mathrm{a}}$, Xiandong Zhao ${ }^{\mathrm{b}}$ and Baocheng $\mathrm{Lu}^{\mathrm{c}}$ \\ Binzhou Polytechnic College, Binzhou 256600, China. \\ a510115338@qq.com, b315722535@ qq.com, c176816963@qq.com
}

\begin{abstract}
Orientation training sergeant" is a new mode for the army to train sergeant relying on local higher vocational colleges. This artical takes Binzhou Polytechnic as an example of the specialty of "Orientation training sergeant", On the basis of analyzing the station ability of "Orientation training sergeant", Analysis of the problems existing in the course system on military and political quality of"Orientation training sergeant",combining the work concerned with the course system of"Orientation training sergeant" in Binzhou Polytechnic The course system of "Orientation training sergeant" was constructed.According to the requirement of ability trained of different curriculum modules, It has innovated the ways of implementing the military and political quality curriculum system of orientated training sergeant, This paper puts forward to the guarantee measures of practicing the course system of military and political quality.
\end{abstract}

Keywords: Orientation training sergeant; curriculum system; military and political quality; direct recruitment of non-commissioned officers; construction.

\section{“定向培养直招士官”军政素质课程体系构建与实践---以滨州职业学院海洋 学院为例}

\author{
宗永刚，赵贤东，陆宝成 \\ 滨州职业学院, 滨州 256600, 中国
}

摘 要: “定向培养直招士官” 是部队依托地方高职院校培养士官的一种新模式。本文以滨州 职业学院 “定向培养直招士官” 专业为例, 在分析 “定向培养直招士官” 的岗位能力的基础 上, 重点分析 “定向培养直招士官” 军政素质课程体系存在的问题, 结合滨州职业学院 “定 向培养直招士官” 课程体系的具体做法, 构建了模块化的 “定向培养直招士官” 课程体系, 并根据不同课程模块能力培养需求, 创新了 “定向培养直招士官” 军政素质课程体系实施的 路径, 提出了实践军政素质课程体系的保障措施。

关键词：定向士官；课程体系；军政素质；直招士官；构建

\section{1. 前言}

定向培养直招士官是为加快培养军队现代化建设需要的高素质士官人才, 从参加全国普通高 校招生考试的毕业生中选拔, 并依托地方优质高职院校培养的一种士官培养模式。经过五年 的发展, 目 前各所院校随着培养工作的不断深入, 各试点单位意识到培养工作遇到了诸多 困难, 主要体现在课程设置不合理, 学员入伍后只能动手操作使用设备, 不具备维修保养设 备的技能; 军政素质课程教师缺乏军事素养, 重理论轻技能; 教学体系不完备, 培养过程不 系统等。 


\section{2. “定向培养直招士官” 军政素质课题体系构建的必要性}

通过对三所承担 “定向直招士官” 培养任务的试点院校随机 263 名准士官问卷调查显示，对 试点单位的军政素质课程开设情况满意度只有 69.96\%, 有超过 30\%的准士官认为目前专业所 开设的军政素质课程无法满足到部队后的发展需求。同时有 40\%的准士官认为目前军政素质 课程的传统教学方法无法满足教学需求。对课程结构的调研数据（如图 1) 显示 “定向直招 士官”军政素质课程结构不合理。

\section{图1 “定向培养直招士官”课程结构调研数据图}

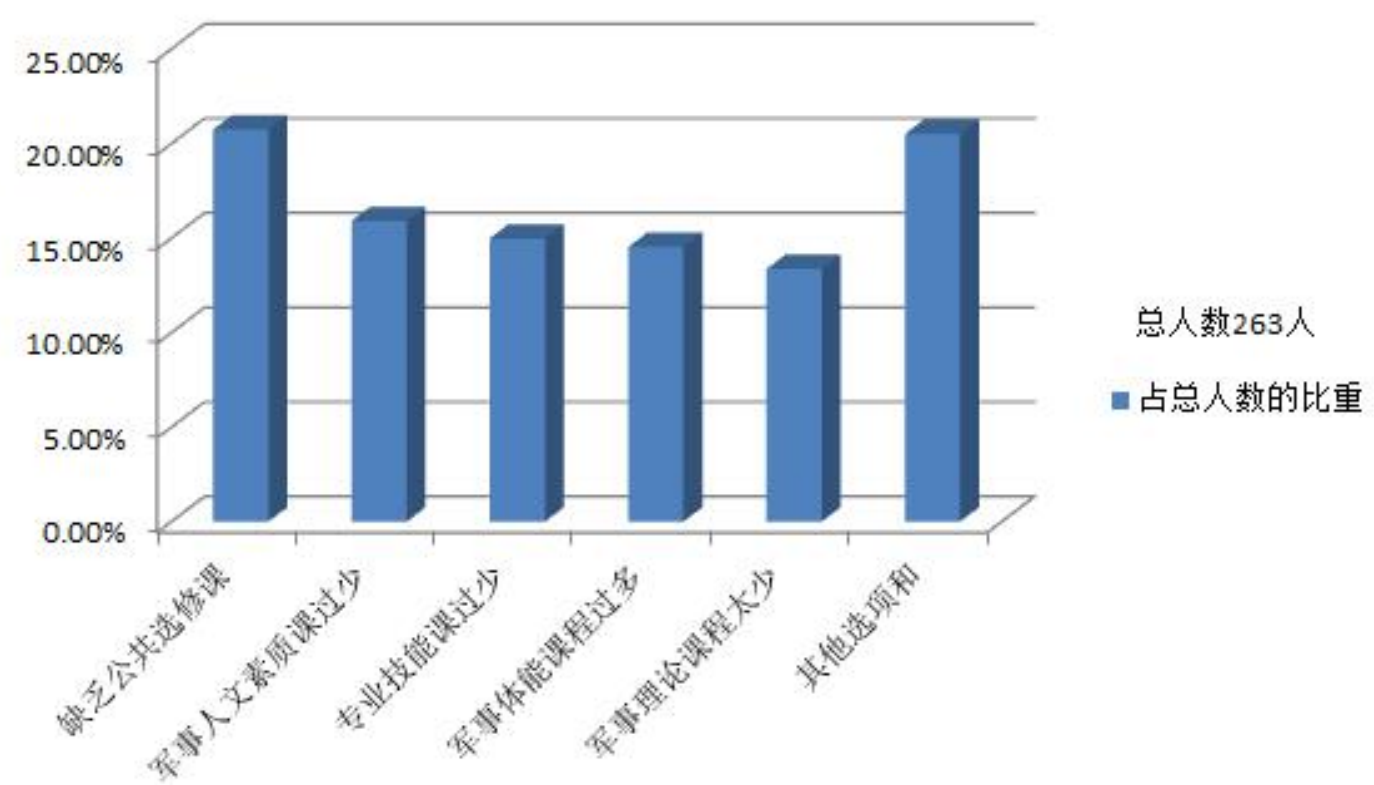

从各试点单位的实践来看, 对定向士官培养机制、人才培养模式等研究已经取得一定研究成 果, 但从深层次分析, 在当前国家高度重视士官教育, 定向培养直招士官军政素质体系建设 进入关键时期的新的历史形势下，构建 “定向培养直招士官” 军政素质课程体系显得尤为重 要。

\section{3. “定向培养士官” 军政素质课程体系的构建}

\section{1 “定向培养士官” 岗位能力分析}

各军种士官是基层部队的军事骨干，承担着一线作战、训练士兵、管理士兵的任务，同时还 是基层部队的技术骨干, 承担着高科技设备的使用、维修和保养的任务。由此可见，士官岗 位具有基层性、技能性，随着士官的职业化，未来士官还具有长期服役性。

基于对士官的职业能力分析, “定向培养直招士官” 在入伍前需要具备基本层次的任职必备 能力, 同时需要具备较高层次的现代化技术发展适应可迁移能力。因此在构建 “定向培养直 招士官” 军政课程体系的时候需要考虑: 能够提高士官的政治觉悟、能够提升士官军事素质、 能够夯实士官理论文化基础、能够扎实士官专业技能、能够培养士官可迁移能力等。

3.2 “定向培养士官” 军政素质课程体系的构建

通过对 “定向培养直招士官” 岗位特性和职业能力的分析, 将 “定向培养直招士官” 军政素 质课程体系分为政治素质模块、军事素质模块、专业素质模块等三大模块。结合滨州职业学 院的实际做法, 构建起 “显隐结合”、“多方联动”、“三双融合” 的军政素质课程体系 (如 图 2)。 


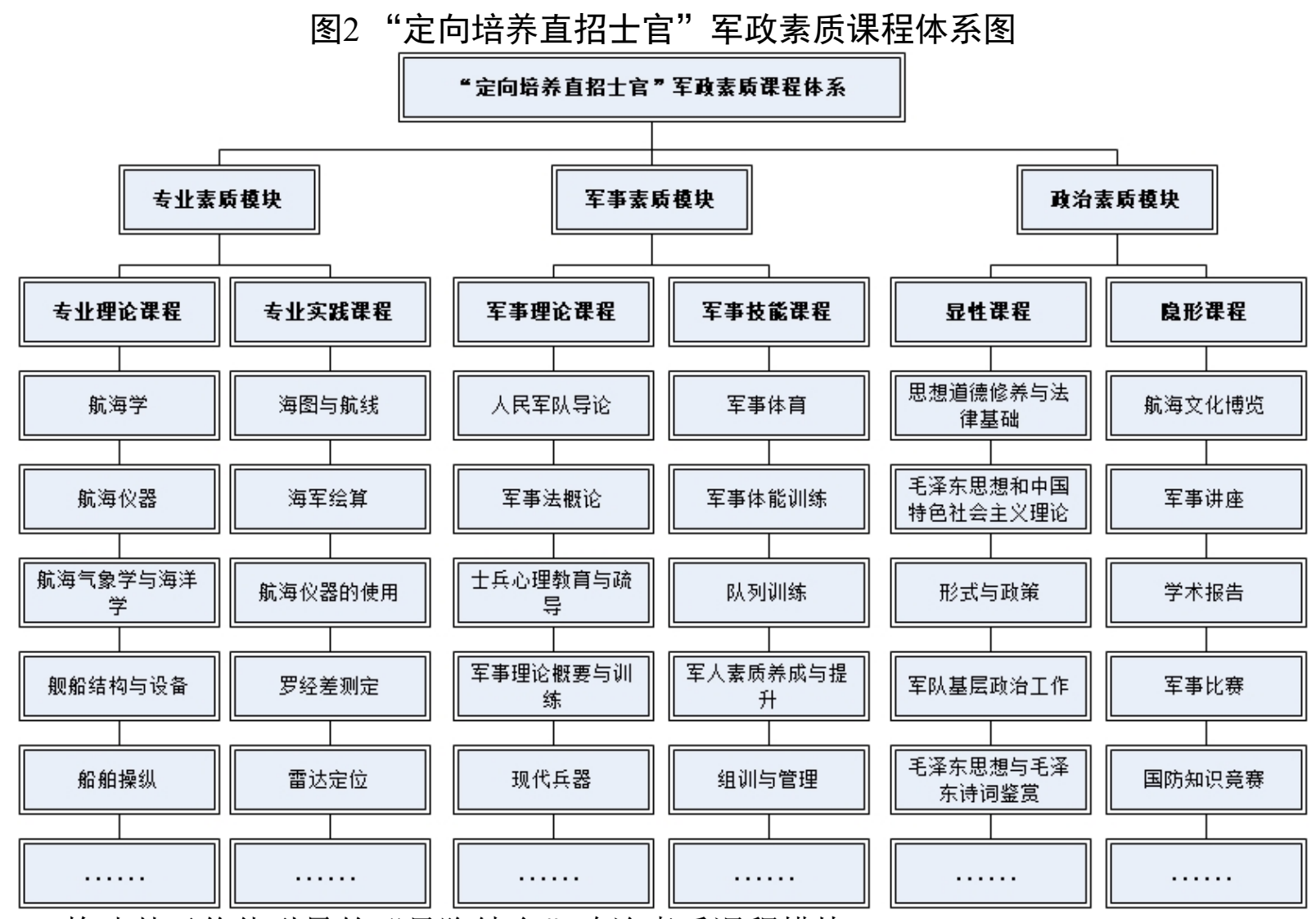

3. 2.1构建基于价值引导的 “显隐结合” 政治素质课程模块

部队士官价值观对士官思想道德和行为方式起着主导作用。在构建课程体系的时候, 基于士 官价值观的引导，设置了 “显隐结合” 政治素质课程模块。政治素质课程模块包含人才培养 方案中明确的通识课程和部队政治素质课程等显性课程, 也包括滨州职业学院为 “定向培养 直招士官”开发的第二课堂、政治讲座、文体比赛等隐性课程（如表 1）。

表1 显隐结合的政治素质课程模块组成

\begin{tabular}{|c|c|c|}
\hline 模块 & 子模块 & 主要课程和形式 \\
\hline \multirow{2}{*}{ 显性模块 } & 通识课程模块 & $\begin{array}{c}\text { 思想道德修养与法律基础、毛泽东思想和中国特色社 } \\
\text { 会主义理论体系概论等课程 }\end{array}$ \\
\hline & 政治素质专业课程模块 & $\begin{array}{c}\text { 军队基层政治工作、军人素质养成与提升、形势与政 } \\
\text { 策教育等课程 }\end{array}$ \\
\hline \multirow{2}{*}{ 隐性模块 } & 部队人文交叉模块 & 军人思想道德修养、海洋观、航海文化博览等课程 \\
\hline & 部队文化建设模块 & $\begin{array}{c}\text { 军事讲座、学术报告、人人都能当教员活动、军事比 } \\
\text { 赛、国防知识竞赛等形式 }\end{array}$ \\
\hline
\end{tabular}

3.2.2构建基于职业活动的 “多方联动” 军事素质课程模块

部队士官的职业活动具有特殊性, 需要士官具备过硬的身体素质、扎实的军事理论知识和娴 熟的军事技能。滨州职业学院搭建了学院、对接训练单位、当地武装部等多方联动的课程平 台, 学院在人才培养方案中设置军事理论课程、军事体能课程, 与当地武装部开展 “联合训 练、联合督查、联合管理”。军事技能课程由当地武装部在其训练基地开设，且当地武装部 成立专门小组负责对学院准士官的日常训练、管理进行独立督查。经常性邀请对接训练单位 对学院准士官教学、管理工作进行指导。 


\section{2. 3构建专业面向的 “三双融合”专业素质课程模块}

部队士官最重要的能力就是专业技能, 而专业技能主要包含两个方面：专业理论技能和专业 实践技能。基于 “定向培养直招士官”专业面向和专业技能培养需求，构建 “双证书”、“双 赛项”、“双实践”三双融合的专业素质课程模块。专业素质模块主要包含专业理论课程、 专业实践课程，其中专业课素质模块为准士官设置了 “水手适任证书” 和 “专业合格证” 两 个证书即 “双证书” ; 为了让 “定向培养直招士官” 更好的掌握专业理论知识和专业实践技 能, 学院为定向培养直招士官设置 “专业理论课程知识竞赛化” 和 “专利实践课程技能大赛 化” , 覆盖全部专业课程和全部知识点、技能点, 且让专业素质课程双赛成为常态。同时整 合实训资源, 将原来分散在各门专业课中的实训项目剥离出来优化整合, 在人才培养方案中 单独设置专业实践课程, 形成专业课融合实践与专业实践课程 “双实践” 的实践课程体系 (如 图 3)。

\section{图3 “定向培养直招士官”专业素质模块构建图}

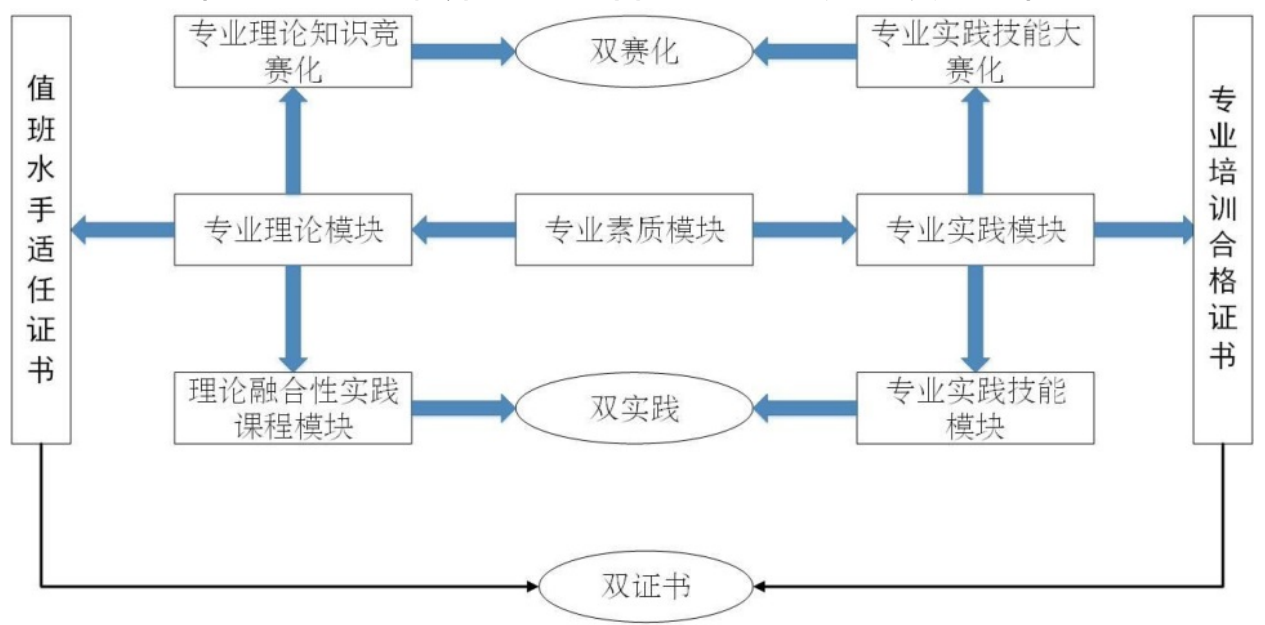

\section{4 “定向培养直招士官” 军政素质课程体系实施的保障措施}

\section{1 制定完善 “定向培养直招士官”考核、淘汰和补充制度}

滨州职业学院为了保障 “定向培养直招士官” 军政素质课程体系的落地, 在 “定向培养直招 士官” 专业实施准军事化管理。并且制定了 “定向培养直招士官” 淘汰补充制度，从组织纪 律、体能考核、课程考核、思想政治、身心健康、资格证书等六个方面对 “定向培养直招士 官” 的考核和淘汰做出了规定。并且制定了 “定向培养直招士官” 缺额补充制度和补充工作 程序。

\section{2 实施 “定向培养直招士官”军政素质课程教学质量评价与诊改工程}

为了保障军政素质课程体系的实施, 滨州职业学院在 “定向培养直招士官” 专业实施军政素 质课程教学质量评价与诊断改进工程。对 “定向培养直招士官” 评价过程中, 采用多主体参 与评价, 由学院、当地武装部和对接训练单位三方参与 “定向培养直招士官” 的评价体系。 注重对 “定向培养直招士官” 的过程性评价, 将士官的过去与现在进行评价, 而非区分不同 学生的优劣。为了“定向培养直招士官” 的全面发展, 在评价过程中注重发展性评价。通过 收集士官和教员的教学过程性数据, 对出现问题的军政素质课程进行诊断并制定改进措施。

\section{5 结语}

本文通过对在校 “定向培养直招士官” 进行调研, 并且分析部队士官岗位能力和技能需求, 确定 “定向培养直招士官” 的需求。结合滨州职业学院的实际做法, 重构 “定向培养直招士 官” 军政素质课程体系, 并且介绍了部分保障 “定向培养直招士官” 课程体系实施的具体措 施, 为定向培养直招士官试点院校提供参考。 


\section{Acknowledgements}

This article is 2015 Shandong vocational education teaching reform research project(A16G071207)results;Results of the 2017 Research Project(2017143)on Vocational Education and Teaching Reform in Shandong Province;2017 Binzhou Polytechnic Vocational Education Reform and Research Project(201714) "Construction and practice on military and political quality training system of higher Vocational College students based on" oriented training sergeant".Thank you for the support of the above project fund.

\section{References}

[1]. Zhao Lianyue.A study on the Construction of the Curriculum system of Humanistic quality Education in Universities: based on the Perspective of the training of basic Education Teachers [J].Talent resources development, 2016(14):199-201.

[2]. Gong Feel Lining. A study on the Construction of "Trinity" practice system with the combination of Humanistic quality and Professional skill of higher Vocational College students [J].Guangxi education, 2015(11):176-177.

[3]. Peng Xuanhong.Some thoughts on how to promote the Reform of Humanities Curriculum and improve students' Professional Literacy-the Construction of Humanistic quality Curriculum system[J].Journal of Yueyang Vocational College, 2012,27(05):17-21.

[4]. Wei Qingpei.The Present Situation and Countermeasures of the Students ' Humanity Quality Education in Police Vocational College[J].Educational modernization, 2017,4(33):108-110.

[5]. Daiyue,Shiguangfei.Research on the training Mode of Non-commissioned officers in Local higher Vocational Colleges[J]Journal of Wuhan Jiaotong vocational college, 2016,18(3):46-49.

[6]. Lilongmei.Journal of Wuhan Jiaotong vocational college [D].Changsha:Journal of Wuhan Jiaotong vocational college,2008.

[7]. Yonggeng Chen.Research on military quality training system of National Defense students in China [D].Changsha:Central South University,2012. 